International Review of Research in Open and Distributed Learning Volume 17, Number 5

September $\mathbf{- 2 0 1 6}$

\title{
Digital Curation as a Core Competency in Current Learning and Literacy: A Higher Education Perspective
}

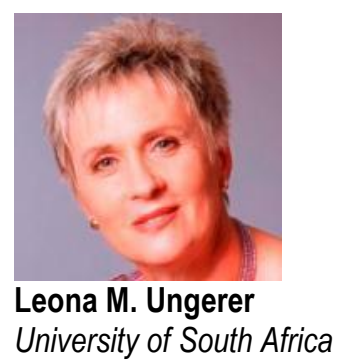

\begin{abstract}
Digital curation may be regarded as a core competency in higher education since it contributes to establishing a sense of metaliteracy (an essential requirement for optimally functioning in a modern media environment) among students. Digital curation is gradually finding its way into higher education curricula aimed at fostering social media literacies. Teachers are urged to blend informal and formal learning and since most people informally use curation in their daily lives for compiling relevant information, it may be fairly easy to adopt digital curation in teaching and learning. Teachers, however, require considerable insight in incorporating various informal digital curation tools in educational practices. The SECTIONS model may assist in guiding decisions around the suitability of digital curation tools for a higher education environment. Including digital literacy training in the professional development of academic staff members may sensitize them to the possibilities that incorporating digital approaches in curricula offer. The Five Cs of Digital Curation framework may guide academic staff members in compiling suitable digital material. There as yet appears not to be a pedagogy that fully acknowledges the various digital curation processes. A pedagogy of abundance, acknowledging that content often is freely available and abundant, may eventually prove relevant in this regard.
\end{abstract}

Keywords: Competency, digital curation, digital literacy, higher education, metaliteracy, openness, pedagogy of abundance, SECTIONS model 


\section{Introduction}

Digital media and networked societies currently figure in most spheres of life. This trend necessitates new individual and collaborative skills (Rheingold, 2012). Openness, embedding practices such as open content, open data and open resources, combined with trends such as transparency and easy access to data and information, further is established as a societal value (Johnson et al. 2013).

People increasingly share information, for instance, by means of audiovisual digital content, hyperlinked web pages, text and multimedia messages, RSS feeds, tweets, and Facebook status updates (Mills, 2013). They mainly preserve and organize online content in highly personalized information spaces. Sharing, appropriation, and collaboration further form the crux of the communication dynamics enabled by digital technologies (Shirky, as cited in Mihailidis \& Cohen, 2013).

Dunaway (2011) suggests that learning landscapes in a digital age are networked, social, and technological. Since people commonly create and share information by collecting, filtering, and customizing digital content, educators should provide students opportunities to master these skills (Mills, 2013). In enhancing critical thinking, we have to investigate pedagogical models that consider students' digital realities (Mihailidis \& Cohen, 2013). November (as cited in Sharma \& Deschaine, 2016), however warns that although the Web fulfils a pivotal role in societal media, students often are not guided on how to critically deal with the information that they access on the Web. Sharma and Deschaine (2016) further point out the potential for personalizing teaching and incorporating authentic material when educators themselves digitally curate resources by means of Web 2.0 tools.

This paper provides a conceptual exploration of the potential and necessity of content curation as a core competency in higher education. It contextualizes the incorporation of digital curation in a higher education environment and points out the relevance of the concept of metaliteracy in this process. Digital curation is clarified, followed by a presentation of some digital curation tools and possible applications of digital curation in a higher education environment. Finally, the SECTIONS model is used to investigate the suitability of digital curation tools in a higher education environment, followed by further suggestions for research and educational applications.

\section{The Changing Context of Higher Education}

Wiley and Hilton (2009) point to considerable disengagement between higher education and society, especially since higher education does not sufficiently acknowledge six particular means in which technological innovations changed society. This causes considerable disparity between higher education and people's daily experiences, as presented in Table 1.

Table 1

The Differences Between Higher Education and the Super-System Embedding It (Wiley \& Hilton, 20o9, p.3) 


\begin{tabular}{|l|l|}
\hline Education & Everyday \\
\hline Analog & Digital \\
\hline Tethered & Mobile \\
\hline Isolated & Connected \\
\hline Generic & Personal \\
\hline Consumers & Creators \\
\hline Closed & Open \\
\hline
\end{tabular}

Technological innovation changed the processes of information capture and dissemination from being analog to digital. Printed media, for instance, are quickly losing ground to digital media (McIntyre, as cited in Wiley \& Hilton, 2009). Mobile phones and wireless devices further allow people to move freely between geographical locations and it is possible to access services such as the Web, Facebook, and instant messaging without being bound to a specific venue.

Technology also enhances a sense of connectedness, instead of feeling isolated. People further connect in real-time by means of social networks, VOIP services such as Skype,and texting. Technology enables combinations of various elements of connectedness, for instance, between people and people, content and content, and systems and other systems that were not possible before.

Technological innovation makes personal approaches conceivable instead of merely adhering to generic approaches. It further is possible to mass customize various types of goods and services. It is, among others, possible to customize a newly purchased laptop based on personal specifications (Wiley \& Hilton, 2009).

Technological innovations changed the role of societal members from consumers to creators of information. People can more easily produce and distribute various cultural artifacts such as books, movies, and music because the necessary tools are fairly freely available in 2016. Anyone can now report on events because of the availability of, for instance, freely available blogging software and mobile phone cameras. Video hosting sites such as YouTube afford opportunities to distribute videos. People therefore no longer simply read and watch: they write, record, and publish information.

Finally, Wiley and Hilton (2009) also point to the societal trend toward openness instead of limiting access to resources. Since the digital distribution of information is affordable, the possibility of widely and freely sharing information is enhanced. Open source software further provides users free, legal alternatives to proprietary software tools. Society currently has access to an incomparable abundance of content that results from major changes in how knowledge is produced and people's relationships with content (Weller, 2011). 
Higher education institutions, however, vary both in the extent to which they acknowledge and respond to changes such as the above (Barnett, 1998). Weller (2011) further points out that existing approaches to teaching and learning were mostly established in an era of scarcity of expertise and content. Barnett (2000), however, points out that higher education has to prepare students for a super-complex world, characterized by features such as ambiguity and changeability. When they are merely learning information or gaining knowledge, students are not adequately prepared for dealing with the complexity and ambiguity embedded in modern society (Betts \& Payne, 2016).

According to Bereiter (as cited in Salas-Pilco, 2013), the core 21st century competencies that students especially need are those that empower them to cope with the demands of current society. These include creativity, being proactive and committed, thinking critically, and being able to collaboratively generate knowledge. They further need information and communication technology (ICT) competencies such as the ability to locate and select relevant information and then produce and share it through various types of media. All in all, they need to be multi-literate (Borsheim, Merritt, \& Reed, as cited in Salas-Pilco, 2013).

\section{Metaliteracy}

Technology considerably impacts on current literacy requirements (Reinking, as cited in Sharma \& Deschaine, 2016). Being literate in the 21st century requires being able to decode and comprehend multimodal texts and digital format and also engage with these texts in a purposeful manner. Literacy is not merely based on a specific skill, but consists of a process that embraces the dynamic, social, and collaborative facets of digital technology (Lewis \& Fabos, as cited in Mills, 2013).

Mackey and Jacobson (2011) suggest reframing the concept of information literacy as metaliteracy (supporting multiple literacy types) because of a tremendous growth in social media and collaborative online communities. They propose that information literacy currently involves more than a set of discrete skills, since active knowledge production and distribution in collaborative online communities are also necessary.

Mackey and Jacobson (2011) position metaliteracy as an overarching and comprehensive framework that informs other literacy types. It serves as the basis for media literacy, digital literacy, ICT literacy, and visual literacy. Students have to be "metaliterate" to efficiently take part in social media and online communities and be able to produce and share content through these media. An understanding of new media tools and original digital information support literacies such as media, digital, and ICT literacy. Students require the abilities to evaluate and apply visual information, both in appreciating visual images and developing new visuals. Information literacy also involves critical thinking that provides an essential base for information fluency and enable people to constantly become accustomed to new technologies.

\section{Metaliteracy in Practice}


Mackey and Jacobson (2011) examine metaliteracy in practice, describing the challenges that emerging technologies hold and offering recommendations for actively engaging students with new media.

Understand format type and delivery mode. In a new media environment, information seekers have to determine the range of information they require, as well as its format and delivery mode. If they require information in non-print formats (e.g., audio, video, and images), they should be aware of the relevant tools for finding them, including Flickr and YouTube, as well as appropriate Web-based tools to upload, tag and share digital information.

Evaluate user feedback. Feedback such as user comments and star ratings may guide information seekers in their search, but they need to contextualize this information by critically evaluating the validity and reliability of all source types, including those that are user-generated. Students need to be aware of the types of tools available and how each functions (Mackey \& Jacobson, 2011).

Create a context for user-generated information. The identity of the person who produced the particular information, as well as his or her level of expertise, may not readily be evident in a Web environment. The current information context therefore requires an increased focus on the evaluation of information sources and a reframing of how to achieve that. In considering the recommendations of others such as tweets, tags, and bookmarks, students should consider the person's level of expertise and distinguish whether a source of information is formal or informal in nature (Mackey \& Jacobson, 2011).

Evaluate dynamic content critically. Information seekers should be able to integrate the various information formats and range of materials available in a Web 2.0 environment. An information literate student should be able to distinguish among facts and opinions in various online forums and determine whether the forum itself is of a formal or informal nature. The assessment of online materials would include the reliability of the media site, the authenticity of materials posted, and the relevance of the user-centred tags and comments (Mackey \& Jacobson, 2011).

Produce original content in multiple media formats. The ability to produce original content is especially important since social media not only provide various means for accessing and evaluating information, but also support multiple uses of information. Information-literate students have to make vital choices about the particular media format for expressing their view and the online site or tool for doing so. Emerging technologies typically present information in a fragmented manner, with links to resources, and interactions tend to be fleeting. Information-literate students have to consider these characteristics when developing their own ideas in online settings (Mackey \& Jacobson, 2011).

Understand personal privacy, information ethics, and intellectual property issues. Although people publicly express their views in social networking and online communities, students still have to consider ethical issues such as personal privacy and intellectual property. It is further necessary to properly attribute sources. A challenge, however, is when authorship is not clear in open and collaborative environments. An information-literate individual should be aware of these information surroundings and understand the impact that they have on our lives (Mackey \& Jacobson, 2011). 
Share information in participatory environments. Information can be accessed and shared in numerous ways via emerging social technology. Web 2.0, for instance, makes it possible to globally communicate information and ideas in various formats. Because of the user-friendliness of social media applications, these tools have expanded rapidly. The supporting skills that contribute to successfully sharing information in these open environments are still essential, including the ability to organize, format, and revise the information to be transmitted (Mackey \& Jacobson, 2011).

All in all, students should be critical participants in the new information environment. They should actively participate in these social environments, query the views of others, critically evaluate the materials that they find and take care when incorporating the information in their own work. Mills (2013) further suggests that students should be allowed to both evaluate and re-apply digital content. By doing so, they will be permitted to not only be consumers of information, but also to moderate and create content.

\section{Digital Curation}

According to Mills (2013, p. 47), digital curation is the sifting and aggregation of internet and other digital resources into a manageable collection of what teachers and students find relevant, personalized and dynamic. It incorporates the vibrancy of components of the Internet and provides a repository that is easily accessible and usable.

A further element mentioned by Mihailidis and Cohen (2013) is that digital curation involves creating a story. Antonio, Martin, and Stagg (2012) highlight the active role of the curator in their definition of digital curation, as follows:

Digital curation is an active process whereby content or artifacts or both are purposely selected to be preserved for future access. In the digital environment, additional elements can be leveraged, such as the inclusion of social media to disseminate collected content, the ability for other users to suggest content or leave comments and the critical evaluation and selection of aggregated content.

This latter part especially is important in defining this as an active process (Antonio et al., 2012). Antonio and Tuffley (2014) further highlight the meta-cognitive processes involved in curating digital content, such as synthesizing, analyzing, and prioritizing information. Rosenbaum (as cited in Betts \& Paine, 2016) also points to the value that curators add during the digital curation process. Curators make qualitative judgments about the information that they gather and organize by adding context and meaning to it.

The above definition applies to four clear but overlapping areas (figure 1), determined by how users primarily use particular tools. The activities involved include blogging and microblogging, social bookmarking, sharing videos and images, with digital curation lying at their core (Antonio et al., 2012). 


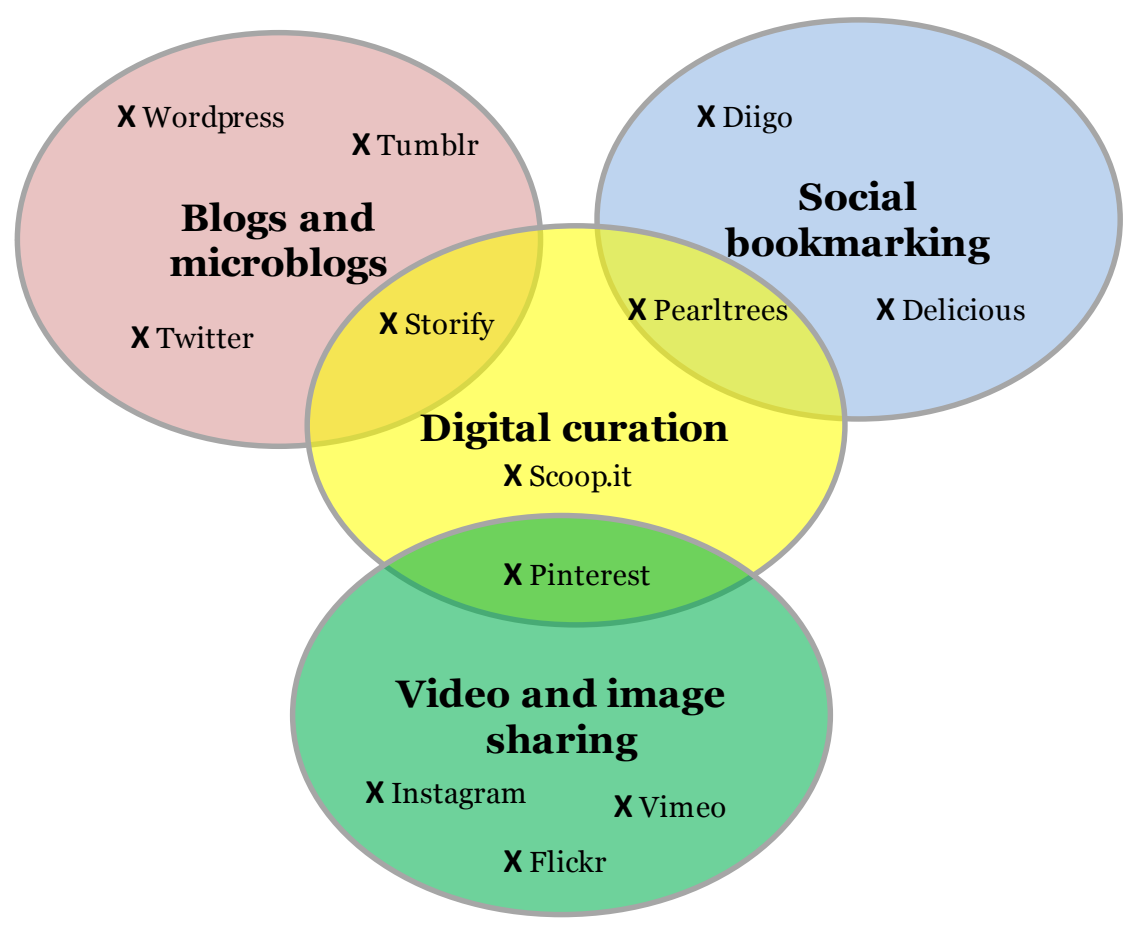

Figure 1. Digital curation tools (Antonio et al., 2012).

Antonio et al. (2012) propose that when digital curation tools (particularly those that they highlighted) are embedded in higher education curricula, it will lead to positive outcomes such as as enhanced student motivation, engagement, and improved learning outcomes. They find the combination of autonomy, engagement, and educational technology in these tools particularly appropriate for sustaining selfdirected learning. In this regard, Betts and Payne (2016) posit that educational programmes will increasingly be designed around self-directed learners. It may consequently be assumed that students are able to curate content and determine its relevance to new contexts without first having to be taught this skill.

\section{Digital Curation Tools}

Academic staff members investigating the option of including digital curation in their curricula will find a variety of freely available, easy to use, and well-designed curation tools on the web (Mihailidis \& Cohen, 2013). On sites such as Facebook, Twitter, YouTube, Pinterest, Storify, Amplify, and Scoop.it, users organize their information based on various types of content and media. These tools in general offer sharing options and the personalization of information.

For the sake of brevity, it is not possible to explain how all digital curation tools function, but Antonio et al.'s (2012) descriptions of a few tools provide valuable guidelines. Scoop.it users delineate the sources that serve as bases for the automated searches that suggest content for their sites and provide keywords for these searches. Since users consider the suggestions for content that they receive, and decide which content to include, they are actively involved in the process. Scoop.it futher contains a social element since 
users may suggest content to other users' sites. Users can also "re-scoop" content from other users' sites to their own collections.

It is possible to both blog and curate content with Storify. Users create a storyline for their site by obtaining content from various sources such as news feeds, websites, and social media. Other users, however, cannot suggest content to their site and it is not possible to direct a content feed by means of keywords.

Pearltrees is similar to social bookmarking. Users can collect web content and visually present the linked content, but they locate the information themselves. On Pinterest, users mainly curate information by posting their content on "pinboards." It is possible to share information, since users can "re-pin" content from other users' sites. Pinterest includes some elements of digital curation, but users cannot suggest content to other users' sites.

\section{Suggestions for Embedding Digital Curation in Higher Education}

Antonio et al. (2012) consider previous applications of digital curation in a higher education environment and provide the following suggestions (Table 2), for incorporating digital curation in particular disciplines.

Table 2

Applications of Digital Curation Tools in Higher Education (Antonio et al., 2012)

\begin{tabular}{|c|c|c|}
\hline Tool & $\underline{\text { Possible use in higher education }}$ & $\begin{array}{l}\text { An extension on the work } \\
\text { of ... }\end{array}$ \\
\hline Storify & $\begin{array}{l}\text { Journalism students: could use Storify to depict a } \\
\text { current story as a series of images and social media } \\
\text { posts to engage a wider, authentic readership. } \\
\text { Political science students: could map an election and } \\
\text { responses to policy in this format }\end{array}$ & $\begin{array}{l}\text { Harsch, } 2011 \\
\text { Markey, } 2011\end{array}$ \\
\hline Pearltrees & $\begin{array}{l}\text { Philosophy students: could evaluate and visually } \\
\text { organize disparate web resources for assessment tasks. } \\
\text { Tutors: could curate and build a visual representation } \\
\text { of resources in their subject areas. }\end{array}$ & Team Plenk, 2010 \\
\hline Pinterest & $\begin{array}{l}\text { Visual arts students: could create a portfolio } \\
\text { showcasing their work whilst gathering inspiration } \\
\text { from others. }\end{array}$ & Yale University, 2012 \\
\hline
\end{tabular}




\begin{tabular}{|l|l|l|}
\hline & $\begin{array}{l}\text { Marketing students: could explore brand image and } \\
\text { social media marketing strategies. }\end{array}$ & Duke University, 2012 \\
\hline Scoop.it & $\begin{array}{l}\text { Literature students: could filter and synthesize web } \\
\text { content, creating an annotated bibliography. } \\
\text { Knowledge management students: could create a group } \\
\text { repository of knowledge. }\end{array}$ & Dixon, 2012 \\
\hline
\end{tabular}

The above suggestions provide a general idea of how digital curation tools may be embedded in a higher education environment and point to some of its positive consequences. Investigating the relationship between digital curation and learning highlights an understanding of some individual-level processes that may support embedding digital curation in higher education curricula.

\section{Digital Curation and Learning}

Considering their functions, Wolff and Mulholland (2013) broadly classify the numerous digital curation tools that are currently available into five basic categories, namely whether they centre around storytelling, collecting, learning, clipping, or publishing, and provide examples of each category, as follows:

- Tools mainly centred around storytelling enable users to create stories by means of tools such as Twitter and Storify by linking web content, especially from social media.

- Tools focusing on collecting information enable users to gather web content around particular themes. It often involves theme-linking, for instance, by means of tools such as BagTheWeb, Pearltrees, and Pinterest.

- Tools that mainly reflect learning enable users to create learning tasks from web content, for instance, by using tools such as Learnist and LiveBinders.

- Tools that mainly incorporate clipping allow users to collect web-clippings, including text selections and visual matter and images from web pages, for instance, by means of a tool such as Clipboard.

- Tools aimed at publishing enable users to curate their own newspaper by selecting news on a particular topic from a number of sources, for instance, by using tools such as Paper.li and Scoop.it (Wolff \& Mulholland, 2013)

In order to determine which tools may be particularly useful in scaffolding students' learning from web content, Wolff and Mulholland (2013) propose a number of questions to identify elements of the curation process that particularly support learning: 
- Do the extent to which students curate content relate to how they learn? Does learning increase when a student progresses in terms of the complexity of curation activities from collecting content to eventually telling and sharing the story?

- Is it beneficial for a learner to build on another learner's content, or should each learner start afresh? If it is advisable to re-curate someone else's material rather than starting anew, how much pre-curated information would be beneficial during each stage of the curation process?

- To what extent do digital tools support the above processes? Does a specific tool allow users to recurate existing content?

Wolff and Mulholland (2013) believe that an understanding of the issues involved in the first two questions will determine the way in which curation tools will be analyzed to respond to the third question. The above issues will now be briefly investigated.

\section{The Relationship Between Curation Processes and Learning}

In order to determine the curation processes that particularly support learning, Wolff and Mulholland (2013) examine the various curation processes and suggest how each may aid learning.

Research. Irrespective of whether the learner or teacher undertakes the research or decides about the task at hand, this step impacts on all stages of the investigation-it delineates the task and guides decisions about the progress that is made (Wolff \& Mulholland, 2013).

Content selection and collection. During content collection, the curator identifies relevant content for a particular task. Although curators assess the content to some extent during this process to confirm its relevance, merely collecting links may not be sufficient for real learning to take place. Annotating each piece of content, for instance, may result in the curator processing the material more deeply (Wolff \& Mulholand, 2013).

Interpretation of individual content (content annotation). Curators determine the relevance of content (they interpret it) based on the learning goal. A particular piece of content may consequently be interpreted in various ways. During content annotation, the student as curator identifies the most relevant content and removes information that is not essential for a particular task (Wolff \& Mulholland, 2013).

Interpretation across content (task annotation). It is essential that students consider content with other items that they have already selected. To understand the relationships between content across resources, it may be advisable to annotate information according to particular tasks and not separate pieces of content. Task annotations assist in making interpretations across groups of content and students can do so by tagging information, adding notes, or selecting relevant sections of resources (Wolff \& Mulholland, 2013). 
Organization. An essential part of the curation process is for students to organize content and annotations according to the fundamental story. This enables students to clearly comprehend the content and is an important requirement for eventually presenting the information. Interpretation often forms part of organization. If a tool allows users to re-organize content and annotations to support the possibility that different items belong to different groupings, it may assist students in interpreting information across content (Wolff \& Mulholland, 2013).

Narration. The organization of content assists students in individually understanding and refining the story, but when they narrate it, they share their insight with other people. By simply "publishing" or "sharing" information (depending on the tool involved), students' stories are publicly available. During narration, students often reflect on whether they sufficiently addressed task requirements (Wolff \& Mulholland, 2013).

To understand some of the issues involved in narration, the issues covered in the second key question have to be addressed: for instance, whether learning is better supported when a student uses a previous learner's (or teacher's) work in guiding the development of their story.

Wolff and Mulholland (2013) recommend an experiment for addressing this issue. They suggest using a marking scheme for assessing students' work, but comparing their outputs on the same tasks and under varying conditions. A number of questions that explore their comprehension of individual content and how much they managed to apply interpretations across content assess their learning and understanding.

The steps described above form the curational inquiry learning process (figure 2), as suggested by Wolff and Mulholland (2013). Although it is not explicitly indicated in figure 2, a student may return to an earlier stage in the inquiry process if necessary and continue with the cycle from there.

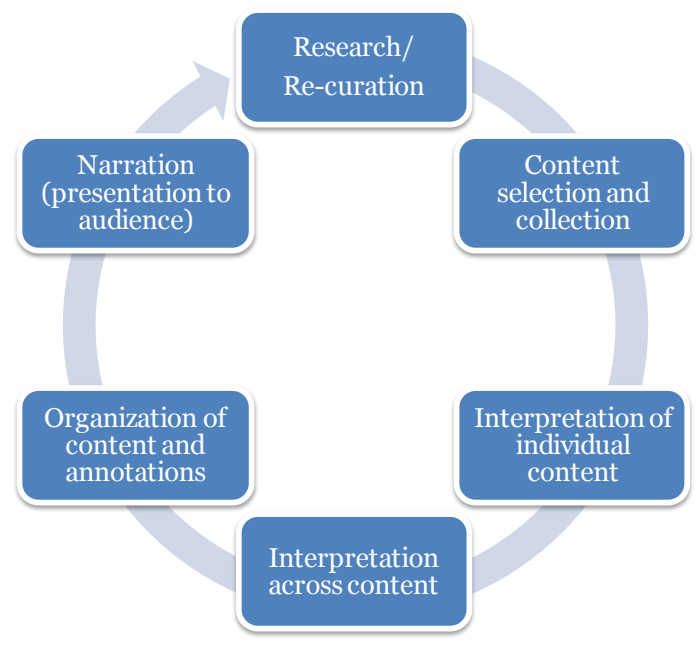

Figure 2. The curational inquiry learning process (Wolff \& Mulholland, 2013).

The Role of Current Digital Curation Tools in Supporting Key Learning Processes 
Wolff and Mulholland (2013) recommend investigating the processes involved in learning via curation since this may enhance an understanding of particular functionalities that support significant learning features. Wolff and Mulholland (2013) therefore investigate the digital curation tools based on the extent to which they support the features they identified earlier (table 3):

- F1: Collecting. The ability to collect content about a particular topic, bearing in mind its source: for instance YouTube and Twitter.

- F2: Interpreting individual content. The extent to which it is possible to annotate content: for instance, by means of tagging, notemaking, or clipping.

- F3: Interpreting across content. The ability to generate task annotations identifying clusters of content.

- F4: Adapting annotations. It should be possible to reconsider and refine annotations during the learning process.

- F5: Organizing. The ability to organize content as well as annotations.

- F6: Narrating. Presenting outputs in a format that is suitable for re-curation.

Table 3

An Analysis of Digital Curation Tools (Wolff \& Mulholland, 2013)

\begin{tabular}{|l|l|l|l|l|l|l|l|}
\hline Tool focus & Tool & F1: collect & $\begin{array}{l}\text { F2: } \\
\text { Interpret } \\
\text { (individual) }\end{array}$ & $\begin{array}{l}\text { F3: } \\
\text { Interpret } \\
\text { (across) }\end{array}$ & $\begin{array}{l}\text { F4: Editing } \\
\text { annotations }\end{array}$ & F5: Organize & F6: Narrate/ \\
recurate
\end{tabular}




\begin{tabular}{|c|c|c|c|c|c|c|c|}
\hline & Pinterest & $\mathrm{I}^{*}$ & Notes & No & Yes & No & Yes \\
\hline \multirow[t]{2}{*}{ Learn } & Learnist & $\mathrm{W}, \mathrm{O}$ & Notes & No & Yes & No & Yes \\
\hline & Livebinders & $\mathrm{W}, \mathrm{SM}, \mathrm{O}^{*}$ & $\begin{array}{l}\text { Notes, } \\
\text { tagging }\end{array}$ & No & Yes & No & Yes \\
\hline Clip & Clipboard & $\mathrm{W}$ & Notes, clips & No & Yes & No & Yes \\
\hline \multirow[t]{2}{*}{ Publish } & Paper.li & $\mathrm{W}, \mathrm{SM}$ & No & No & $\mathrm{N} / \mathrm{A}$ & No & Yes \\
\hline & Scoop.it & $\mathrm{W}, \mathrm{SM}$ & Notes, tags & No & Yes & No & Yes \\
\hline
\end{tabular}

Note. $\mathrm{W}=$ =web content; SM=social media (Facebook, Twitter, YouTube, Flickr); I=images; $\mathrm{O}=$ own content

Wolff and Mulholland (2013) find that most applications are suited to content annotation, but they vary significantly in terms of the extent to which notes can be edited or easily viewed along with content. Only Storify offered the possibility of using task-related annotations to interpret information across content without being linked to specific sections of content. The convenience of this feature alleviates the most important concern about Storify to some extent, namely that it does not provide sufficient flexibility in terms of individual content annotation.

Most sites further do not offer users a substantial degree of flexibility in organizing the content that they collect. Users collate information in a linear format on most sites, with Pearltrees being the exception since its users do not necessarily collect content in a chronological order. All sites are suited to re-using content and it is relatively easy to add items from other sites to most of these sites.

All in all, digital curation encompasses research and inquiry methods and each stage of the curatorial process incorporates preceding steps. Wolff and Mulholland (2013) therefore propose that students learn more the further along the curation process they progress. They also, however, advise that since many digital curation tools merely focus on content collection, even those focused on learners often do not maximally draw on the possibilities offered by the curation process. Mills' (2013) approach may address this limitation since he takes a somewhat broader approach and includes what he terms "curation resources" instead of digital curation tools.

\section{Using Digital Curation to Facilitate Multi-literacy Instruction}

Mills (2013) suggests that when educators develop authentic digital projects and assessments, students' engagement and readiness to collaborate on material of interest will be enhanced. Carefully planned digital curation tasks may guide students to gradually become skilful in digital content curation, eventually resulting in enhanced multimodal literacy. 
Students, however, should be taught the skills required to access the relevant information and filter it for a specific purpose and audience. Mills (2013) proposes that this does not really differ from the requirements for writing projects. What distinguishes digital content curation, however, is the possibility of personalizing, customizing and sharing the information in a uniquely personal way. Sharing is an essential element in the curation process since it enables others to observe and learn from the curator's outputs (Betts \& Payne, 2016).

Students need a clear outline for designing a digital content curation project, including some solutions and recommendations to guide them in this process.

\section{The Digital Curation Process in Literacy Instruction}

To be effective digital content curators, students should be able to:

- $\quad$ consume and comprehend multiple forms of content on the web;

- $\quad$ aggregate content based on a specific purpose;

- evaluate the content's usefulness, timeliness, and credibility;

- contextualize and repurpose the content appropriately;

- $\quad$ prioritize and reformat the content according to a purpose; and

- $\quad$ share the material and collaborate with the intended audience.

\section{Consuming and Comprehending Multiple Forms of Content on the Web}

In order to select and customize digital content for curation, it first needs to be consumed. That is, digital content has to be found and its core and underlying messages identified. The aim is to find specific content that will later be collected and filtered for the relevant audience, as well as gain as much information as possible about a variety of related subjects so that a reader can form a broad understanding of a topic to facilitate contextualizing the topic later in the process.

\section{Aggregating Content Based on a Specific Purpose}

Students should define the purpose of the curated site, since it serves as a filter to sift through content that they have already discovered. Selecting and compiling content, however, requires an understanding of the range of aggregation and curation resources available on the web. Many of these resources correspond quite closely, often merely differing in terms of types of layout or levels of interactivity. Mills (2013) identifies a variety of web resources and mobile applications to facilitate the aggregation process (table 4).

Table 4

Digital Curation Resources (Mills, 2013, p 54) 


\begin{tabular}{|c|c|c|c|c|c|c|c|c|c|}
\hline Curation resource & 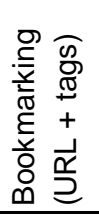 & 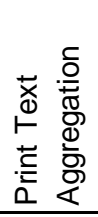 & 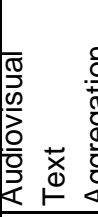 & 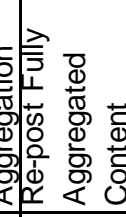 & 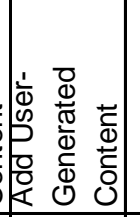 & 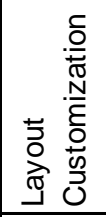 & 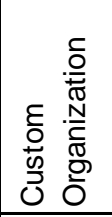 & $\begin{array}{l}\text { D } \\
\frac{.}{\bar{\sigma}} \\
\frac{\pi}{\omega} \\
\end{array}$ & 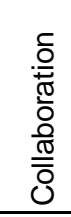 \\
\hline Bundlr & & $x$ & $x$ & $\mathrm{x}$ & & $x$ & $x$ & $x$ & $x$ \\
\hline Clipboard & $\mathrm{x}$ & $\mathrm{x}$ & $x$ & $\mathrm{x}$ & & $x$ & $x$ & $\mathrm{x}$ & $x$ \\
\hline Diigo & $x$ & & & & & & $x$ & $x$ & $x$ \\
\hline Evernote & $\mathrm{X}$ & $x$ & $x$ & $x$ & $x$ & $x$ & $x$ & $x$ & \\
\hline Flickr & & & $x$ & & $x$ & $x$ & $x$ & $x$ & $x$ \\
\hline Flipboard & & $x$ & $x$ & & & & $x$ & $x$ & \\
\hline Google Reader & & $x$ & & & & $x$ & $x$ & $x$ & $x$ \\
\hline iBooks Author & & & & & $x$ & $X$ & $x$ & & \\
\hline Instapaper & & $x$ & & & & & $x$ & $x$ & \\
\hline Learni.st & $x$ & & $x$ & $x$ & & & $x$ & $x$ & $x$ \\
\hline LiveBinders & $x$ & $x$ & $x$ & $x$ & & & $x$ & $x$ & $x$ \\
\hline Pearltrees & $x$ & $x$ & $x$ & $x$ & & $x$ & $x$ & $x$ & $x$ \\
\hline Pinterest & $x$ & & $x$ & $x$ & & & $x$ & $x$ & $x$ \\
\hline Pocket & $x$ & $x$ & $x$ & & & & & & \\
\hline Scoop.it & & $x$ & $x$ & $x$ & & $x$ & $x$ & $x$ & $x$ \\
\hline Springpad & $x$ & $x$ & $x$ & $x$ & $x$ & $x$ & $x$ & $x$ & $x$ \\
\hline Storify & $x$ & $x$ & $x$ & & $x$ & $x$ & $x$ & $x$ & $x$ \\
\hline Tumblr & $x$ & $x$ & $x$ & $x$ & $x$ & $x$ & $x$ & $x$ & $x$ \\
\hline Twylah & & $x$ & $x$ & & & $x$ & $x$ & $x$ & $x$ \\
\hline Wikispaces & $x$ & $x$ & $x$ & $x$ & $x$ & $x$ & $x$ & $x$ & $x$ \\
\hline Zite & & $x$ & $x$ & & & & $x$ & $x$ & $x$ \\
\hline
\end{tabular}

Several digital resources are available for curators to aggregate, customize, and share content. Some resources are limited to simply marking the URL of a webpage for later retrieval or sharing and others aggregate text and audiovisual content for consumption and allow customization and the inclusion of user-generated content. Table 4 indicates which capabilities exist for each of the curation resources. Each feature facilitates at least one general aspect of the digital curation process: (1) collecting, consuming, and filtering; (2) customizing or creating content; and (3) sharing and collaborating content. The hardware and software platforms that are used when sharing the curated content and collaborating with others also need to be considered.

\section{Evaluating the Content's Usefulness, Timeliness, and Credibility}

In filtering the content that will be published and eventually shared, the curator considers the needs of his or her audience. When the curator targets a specific audience and with a specific purpose in mind, it increases the focus and the complexity of the curation process (Anderson, 2016).

Similar to authoring a paper, the curator creates a published artifact. Wiggins (as cited in Mills, 2013) advises that the curator should minimize information overload by being concise and only include what is remarkable and useful. Empathy with the audience promotes maintaining readability, facilitates sharing, and aligns the purpose and focus of the curated site with the interests of the audience. 


\section{Contextualizing and Repurposing the Content Appropriately}

Mills (2013) believes contextualization is what distinguishes curation from aggregation. A curator customizes the content for the intended audience since it is supposed to be shared and to engage the audience. Customization involves prioritizing, reformatting, and editing the aggregated content. To enhance accessibility and readability, the curator must edit content, for instance, rephrasing the title of a web page so that it accurately highlights the aspect of the content that appeals to the intended audience.

\section{Prioritizing and Reformatting the Content According to Purpose}

During prioritization, the curator ranks content according to the criteria considered appropriate for the particular site. In determining which content will be accessed, the curator provides his or her formal approval, which may influence perceptions of the curator's expertise based on whether the content is truly useful and engaging. During the prioritization of digital content, content is often re-ordered. Curators and users therefore interact with each artifact and each chunk of information as objects that can be manipulated.

\section{Sharing the Material and Collaborating with the Intended Audience}

Mills (2013) mentions that all the digital curation resources in Table 4 offer means by which to share curated content by means of popular networking sites like Facebook, Twitter, or LinkedIn, but the content of the sites themselves can also be linked directly by means of shared links or HTML code, embedded in another person's blog or another website. The audience for curated content may be only the curator (by not sharing embed codes or hyperlink information, or by setting the privacy controls) or it can be the curator's network of colleagues, friends, and acquaintances, if the link is e-mailed, liked, tweeted, or shared on a variety of other social networking sites.

A link can also simply be provided on the page that enables the audience to view and share (and even modify) the content. This forms the core of how digital curation can be applied in dynamic collaboration. Mills (2013) advises that the nature of literacy involved shifts with each collaboration and may change significantly from text to multimedia or interactive content. Since this shifting of content may make it difficult or even impossible for the teacher to evaluate students' understanding of the content, it may be advisable to determine mastery of the instructional objective by focusing on the process instead of merely on content.

In summary, it is evident that multi-literacy is an essential attribute in the current information environment. A focus on metaliteracy should support students in developing skills that can be transferred to various other learning situations, for instance, when interacting with different media and platforms (Dunaway, 2011). Good (2016) further advises that if education aims at introducing students to the essentials of the learning process, to know where to find information and pinpoint the relevance of available information for achieving particular goals or objectives, curation will play a vital role in future education. Higher education institutions may therefore consider incorporating digital curation in their pedagogical practices to advance multi-literacy among their students. 
The final section elaborates on practical considerations for incorporating digital curation tools and resources in a higher education context.

\section{Incorporating Digital Curation Tools in a Higher Education Environment}

Concrete benefits to users should guide decisions about the selection and use of a particular type of technology for education. Bates and Poole (2003) advise that decisions about technology should always be contextualized. They propose the SECTIONS model to guide decisions when choosing technology, both at strategic and tactical level.

\section{The SECTIONS Model}

The criteria are as follows.

S. Students: Which level of higher education is the technology especially suitable for? Is it suitable for a particular group or a range of students? Digital curation tools, if carefully selected, could be used across all levels of higher education, ranging from first year to postgraduate studies. Students should be gradually introduced to these tools and some scaffolding of the process needs to be considered. It may be advisable to determine which digital curation resources students already are familiar with, as well as which tools may particularly assist them in cultivating the types of literacy that they need at a particular level of study. The introduction process should be staggered across various levels of study in a particular department to ensure consistency.

E. Ease of use and reliability: How easily can both teachers and students use the technology? Is the technology well-tested and reliable? Are tutorials available? Good curation may be time-consuming and to ensure the success of this process, both curators and learners have to find the particular platform easy to use (Anderson, 2016).

A variety of freely available digital curation tools (primarily open source and web-based) is available on the Internet. Tools such as Pinterest are based on a highly visual approach, while text and images can be integrated to a larger extent through tools such as Learnist, Pearltrees, Storify, and BagTheWeb, to create a visual magazine style artifact (Flintoff, Mellow \& Clark, 2014). According to Anderson (2016), the abundance of currently available tools fuels an interest in curation. It allows people with sufficient experience or enthusiasm about a particular topic to curate valuable collections (Good, 2016). Visually engaging and powerful tools that are easy to use enhance their flexible application (Anderson, 2016).

It is evident that these applications in general tend to be user-friendly. A concern, however, is that most were not developed for educational purposes and teaching staff therefore have to locate tools that endorse particular teaching and learning goals. Affordability and sustainability of access may also have to be considered.

Academic staff who consider undertaking digital curation themselves, may benefit from the Five Cs (collection, categorization, critiquing, conceptualization, and circulation) Digital Curation framework, 
developed by Deschaine and Sharma (2015). According to Sharma and Deschaine (2016), their framework guides academic staff when using Web 2.0 resources in developing items that meet professional teaching standards. Their framework should assist academic staff in developing learning units that provide a deeper, more meaningful context for student learning than merely relying on prescribed books.

C. Costs: What are the costs involved in each technology? A variety of freely available digital curation tools are accessible on the Web (Flintoff et al., 2014). According to Sharma and Deschaine (2016), it would be virtually impossible to list all the Web 2.0 tools that academic staff members can apply during curation, particularly since technology is constantly evolving. Suggesting that certain tools will always be suitable during each of their five stages would be an oversimplification of the recommended digital curation process.

Sharma and Deschaine (2016) do, however, share the 10 free content curation tools that they frequently use and that may be useful in certain instructional contexts.

Table 5

Ten Recommended Content Curation Tools (Sharma \& Deschaine, 2016)

\begin{tabular}{|c|c|}
\hline Curation Tool & Potential for Curation \\
\hline Google Docs (docs.google.com) & $\begin{array}{l}\text { - facilitates the creation, editing, and sharing of text } \\
\text { documents, with the notable feature of real-time } \\
\text { collaboration. }\end{array}$ \\
\hline $\begin{array}{l}\text { LiveBinders } \\
\text { (www.livebinders.com) }\end{array}$ & $\begin{array}{l}\text { - enables users to create and store content, curated in a three- } \\
\text { ring binder, for the Web. }\end{array}$ \\
\hline Protopage (www.protopage.com) & $\begin{array}{l}\text { - a collection tool that enables users to aggregate content in a } \\
\text { bookmark-style dashboard }\end{array}$ \\
\hline $\begin{array}{l}\text { Pinterest } \\
\text { (https://www.pinterest.com) }\end{array}$ & $\begin{array}{l}\text { - an online tool for creating and sharing visual boards of } \\
\text { collections. Users can categorize and circulate their boards. } \\
\text { - also offers collaborative boards. }\end{array}$ \\
\hline $\begin{array}{l}\text { Google Drive } \\
\text { (https://www.google.com/drive) }\end{array}$ & $\begin{array}{l}\text { - enables users to access and share files, such as Word } \\
\text { documents, photos, and video files, anywhere through secure }\end{array}$ \\
\hline
\end{tabular}




\begin{tabular}{|c|c|}
\hline & $\begin{array}{l}\text { cloud storage. } \\
\text { - is part of the Google Classroom suite } \\
\text { (https://classroom.google.com). }\end{array}$ \\
\hline Learnist (learni.st) & $\begin{array}{l}\text { - allows users to create content that is specifically designed to } \\
\text { support people who want to learn more about a topic or } \\
\text { content area (similar to Pinterest). }\end{array}$ \\
\hline Pearltrees (www.pearltrees.com) & $\begin{array}{l}\text { - free space online to organize all user's areas of interest into } \\
\text { one place. } \\
\text { - encourages users to explore the content assembled by others } \\
\text { to meet their own instructional and interest needs. }\end{array}$ \\
\hline $\begin{array}{l}\text { Edmodo } \\
\text { (https://www.edmodo.com) }\end{array}$ & $\begin{array}{l}\text { - a free teaching and learning support site that functions like a } \\
\text { learning management system. } \\
\text { - allows teachers, students, and parents can find new } \\
\text { resources and mutually collaborate on instructional } \\
\text { activities. }\end{array}$ \\
\hline Scoop.it (www.scoop.it) & $\begin{array}{l}\text { - a free way to discover new content and information and } \\
\text { curate and publish content in a way that generates interest } \\
\text { and gains online visibility. }\end{array}$ \\
\hline TouchCast (www.touchcast.com) & $\begin{array}{l}\text { - integrates all forms of multimedia into a cohesive } \\
\text { presentation. }\end{array}$ \\
\hline
\end{tabular}

T. Teaching and learning: Which types of learning does this technology particularly encourage? Digital curation tools and resources tend to support learning that is student-centred and collaborative. Students also have an opportunity to reflect on the content and the process of learning. According to Antonio et al. (2012), the tools that they considered particularly foster a sense of ownership 
among students and they may personalize students' learning. Students also gain a sense of autonomy in creating their digital collections.

Digital curation indeed supports a "participatory culture" (Jenkins et al., 2009) since technology enables ordinary users to interact with media content in new manners: for instance, they can archive, annotate, and recirculate it. It further is evident that a digital curatorial learning cycle can be established if digital curation is efficiently incorporated in curricula.

Antonio and Tuffley (2015) investigated how a goal-setting strategy, combined with the integration of technology in the curriculum, could promote engagement among university students. They requested a group of first-year university students to determine a clear goal in terms of their ideal future careers and then curate content (research and present their findings) by means of the digital curation tool Scoop.it.

Students collected at least five pieces of digital content relating to their topics, justified their choices by means of comments, and submitted the Scoop.it URL when the assignment was due. Antonio and Tuffley (2015) found that students were particularly engaged in this task because, as ICT students, they could apply their existing digital literacy skills and the task was relevant to their career goals. Students also expressed their preference for this type of assignment as compared to conventional assignments.

I. Interactivity: What type of relations do this technology support? If applied properly, digital curation tools may hold new opportunities for students to interact with learning material, their peers, and academic staff members. Students' engagement and motivation may be enhanced during this process (Hazari, North, \& Moreland, 2009).

Antonio and Tuffley (2014), for instance, investigated the suitability of Scoop.it as a networking tool for first-year students enrolled in a first-semester ICT course. Students found Scoop.it particularly useful for sharing their ideas and resources with peers who were collecting resources in an area similar to theirs (therefore, applying it in educational networking). Students, however, did not find the platform particularly useful for socialization (applying it for social networking).

Digital curation further allows academic staff members to move beyond the confines of their classrooms because the material that they create may be used by learning communities accross various instructional areas (Sharma \& Deschaine, 2016).

O. Organizational issues: What organizational requirements need to be considered and which barriers have to be removed for this technology to be used effectively? A challenge that higher education institutions may face in adopting digital curation tools and resources is varying levels of digital literacy among students and academic staff members. According to Johnson et al. (2013), the critical skills and techniques that support digital literacy are often not formally taught and students and educators informally acquire some of the required skills. By 2015, Johnson et al. (2015) indicated that the concept of digital literacy is now better understood and higher education institutions realize that they should suitably prepare academic staff members for establishing digital literacy among students. 
Continuing training is necessary to prepare academic staff members for intregrating digital literacy into curricula. It is therefore advisable to incorporate opportunities for enhancing digital literacy in the professional development of academic staff members. If they are to provide students with some scaffolding in applying a particular curation tool, they should be fairly familiar with what students may expect during the curation process, suggesting some ease in a digital environment.

Betts and Payne (2016) distinguish between curation and learning mindsets. They point out that these mindsets may co-exist, but emphasize that mere learning or knowledge acquisition do not sufficiently provide for dealing with the complexity and ambiguity in current society.

Table 6

Characteristics of a Curation Mindset and a Learning Mindset (Betts \& Payne, 2016, p. 10 )

\begin{tabular}{|l|l|}
\hline Curation Mindset & Learning Mindset \\
\hline shares as part of insight & shares as an afterthought \\
\hline invites comment & sometimes welcomes comment \\
\hline adds value by annotation & annotates to understand \\
\hline understands by communicating & understands by reflecting \\
\hline aims for collective understanding & wants to understand as an individual \\
\hline builds and lives in networks & sees networks as an additional bonus \\
\hline makes meaning & makes understanding \\
\hline focuses on the learning organization & focuses on the individual \\
\hline welcomes ongoing dialogue & accepts isolated dialogue \\
\hline gains insight by others' contribution & gains understanding by working alone \\
\hline shares in the process of understanding & shares only when understood \\
\hline
\end{tabular}

When incorporating social media technologies in teaching and learning, the learning paradigms of higher education institutions change considerably. In such situations, educators do not represent the main sources of information and knowledge and students collobrate in sharing and creating content, reflecting a social constructivist model (Antonio \& Tuffley, 2014).

According to Betts and Payne (2016), curation offers a significant competitive edge by supporting new perspectives on the environment and knowledge generation, which may significantly impact people's 
work experiences. Developing this competitive edge, however, requires suitable tools and processes, the relevant mindset, and an environment in which activities such as digital curation are rewarded.

Since the digital curation process can be time-consuming, Betts and Payne's (2016) suggestion that the curator's own knowledge and insight are enhanced when curating content for others may not sufficiently enourage busy academic staff members to take up this activity. Wolski and Richardson (2014) advise that terms such as "digital scholarship" and "transformative scholarship" highlight new ways in which academics embrace innovative research practices. Considering Rumsey's (as cited in Wolski \& Richardson, p. 85) definition of digital scholarship, namely "the use of digital evidence and method, digital authoring, digital publishing, digital curation and preservation, and digital use and reuse of scholarship," academic staff members may eventually receive recognition for their involvement in digital curation in this area.

N. Novelty: How new is this technology? Most digital curation tools and resources are not considered novel anymore. Applying them to enhance learning outcomes in an educational context, however, may be fairly novel.

Deschaine and Sharma (2015) argue that since academic staff have to impart twenty-first-century skills to their students, they should become digital curators, demonstrating their practical knowledge of digital material and resources by incorporating resources that support the objectives embedded in curricula in their teaching.

Academic staff may also have to develop a sense of metaliteracy. Sharma and Deschaine (2016), for instance, advise that they have to critically investigate the relevance of material that they consider using. If they aim at maintaining the intellectual property rights to their work, they should carefully consider where they circulate their materials. All teaching material further is not necessarily openly accessible.

\section{S. Speed: Is it possible to quickly incorporate this technology into courses? How} much time is needed for materials to be changed? Most digital curation tools and resources can be incorporated fairly quickly into courses, especially if it is only to a limited extent and to introduce students to some of the possibilities that these tools offer.

Academic staff members are used to identifying, locating, and assessing suitable academic materials to incorporate into their teaching. Technological advances, however, currently enable them to manage this process much more efficiently (Deschaine \& Sharma, 2015). Good (2016) advises that curation may soon directly impact how we teach competencies, how we compile textbooks, and how we guide students' learning about a subject.

Weller (2011) points out that although a major shift in education could be expected in the light of the current profusion of content and connections, it has not yet been sufficiently acknowledged in a model of teaching. He investigates a number of existing learning theories as possible pedagogies of abundance to reflect a more participatory, socially constructed view of knowledge. These theories may also present a 
starting point in searching for a suitable theory that embeds digital curation in the knowledge generation process.

\section{Pedagogies of Abundance}

According to Weller (2011), a pedagogy of abundance should consider a number of assumptions such as that content often is freely available and abundant. Content further takes on various forms and it is often easy and inexpensive to share information. Content is socially based and since people filter and share content, a social approach to learning is advisable. Further, establishing and preserving connections in a network is easy and they do not have to be maintained on a one-to-one basis. Successful informal groupings occur frequently, reducing the need to formally manage groups.

Weller (2011) examines some pedagogies that acknowledge some of the above assumptions as possible pedagogies of abundance.

Resource-based learning. Ryan (as cited in Weller, 2011) defines resource-based learning as "an integrated set of strategies to promote student centred learning in a mass education context, through a combination of specially designed learning resources and interactive media and technologies." Since it acknowledges the abundance of resources, resource-based learning appears suited as pedagogy of abundance. Weller (2011), however, contends that it still too strongly reflects a scarcity approach since the integrated strategies incorporate a number of instructional design principles to develop learning materials. Weller (2011) recommends focusing on selecting, aggregating, and interpreting existing materials instead of developing specific learning materials.

Problem-based learning. Problem-based learning takes place when learners experience the process of working toward resolving a problem encountered early in the learning process (Barrows \& Tamblyn, as cited in Weller, 2011). Students often collaborate in small groups to identify solutions to illdefined problems, while the teacher acts as facilitator and assists groups if they need help. Problem-based learning meets a number of important requirements such as being learner-directed, using diverse resources and taking an open-ended approach. This theory however, may require further adaption to reflect the current abundance of content, with a greater emphasis on identifying and evaluating a variety of resources, including social networks.

Constructivism. Constructivism focuses on individual learners who construct their own knowledge by means of mental activity (Jonassen, as cited in Weller, 2011). Because of their distinctive set of experiences, people further perceive their external reality somewhat differently.

Mayer (as cited in Weller, 2011) believes guided approaches to learning are more effective than discoverybased approaches such as constructivism. Since publishing content in a Web 2.0 world is fairly open, this may be a valid concern. However, since open publishing is a fairly established trend in the developed world people should be able to construct relevant, accurate knowledge from a variety of sources. 
Communities of practice. Lave and Wenger's (as cited in Weller, 2011) concept of situated learning and Wenger's (as cited in Weller, 2011) idea of communities of practice highlight the importance of apprenticeship and the social role in learning.

They proposed that participants move to the centre of of a community by taking part in acceptable tasks. Weller (2011) believes that the communities of practice approach typically found in open source communities offers an appealing possibility as pedagogy of abundance considering the practical approach that it follows, the importance attached to self-direction, the use of user-generated content and its innate social aspect. The number of successful open source communities, however, appears limited and the requirements for successfully generating and sustaining an effective community are not yet clear.

Connectivism. The only post-network theory that Weller (2011) considers is connectivism, a learning theory proposed by George Siemens. This theory stresses that learning takes place in a network and acknowledges that learning and knowledge result from diverse opinions. The objective of all connectivist learning activities is to establish accurate, current knowledge. Weller (2011) concludes that since it highlights the significance of networks and connections, connectivism probably most closely resembles a pedagogy of abundance. However, although it incorporates both comprehensible principles and other theories, it not yet regarded as an established pedagogic theory.

\section{Conclusion}

Ng'ambi and Bozalek (2013) point out the increasing concern that current higher education teaching practice does not sufficiently develop the relevant competences, capabilities, and attributes that students require in the workplace. It, however, is the responsibility of higher education institutions to equip their graduates with the necessary skills and competencies for employment in a knowledge society (Ghaith, 2010; Peterson, 2016).

Curation occupies a central position in the meaning-making process in a digital age (Betts \& Paine, 2016). Digital curation indeed appears to offer opportunities for employing internet resources in dynamic, student-centred, socially-interactive approaches to support an inquiry-based pedagogy aimed at enhancing student engagement and multimodal literacy comprehension (Mills, 2013). Both students and teachers should be encouraged to become digital curators who not only consume information that they find on the internet, but also evaluate and synthesize it to eventually become responsible digital citizens.

Curation plays an essential role in the learning process and serves as an important digital literacy requirement for knowledge workers (Betts \& Payne, 2016). Positioning curation as a digital literacy further enriches current conversations about digital literacy and educational technology (Bhatt, 2015). More research on the application of digital curation in educational settings, however, is needed, particularly its acknowledgement in digital scholarship and embedding it in a pedagogy that truly considers the principles of abundance and a participatory culture. 


\section{References}

Anderson, A. (2016). Creating your curation strategy. In A. Anderson \& B. Betts (Eds). Ready, set, curate (pp. 14-21). Alexandria, VA: Association For Talent Development.

Antonio A., Martin, N., \& Stagg, A. (2012). Engaging higher education students via digital curation. Retrieved from https://eprints.usq.edu.au/22515/3/Antonio Martin Stagg ascilite 2012 PV.pdf

Antonio, A., \& Tuffley, D. (2014). Creating educational networking opportunities with Scoop. it. Journal of Creative Communications, 9(2), 185-197.

Antonio, A., \& Tuffley, D. (2015). First year university student engagement using digital curation and career goal setting. Research in Learning Technology, 23. Retrieved from http://www.researchinlearningtechnology.net/index.php/rlt/article/view/28337

Barnett, R. (2000). Supercomplexity and the curriculum. Studies in Higher Education, 25(3), 255-265, DOI: $10.1080 / 713696156$

Barnett, R. (1998). Supercomplexity and the university. Social Epistemology: A Journal of Knowledge, Culture and Policy, 12(1), 43-50, DOI:10.1080/02691729808578859

Bates, A.W., \& Poole, G. (2003). Effective teaching with technology in higher education: foundations for success. San Francisco, CA: Jossey-Bass.

Betts, B., \& Payne, N. (2016). From content to curation. In A. Anderson \& B. Betts (Eds). Ready, set, curate (pp.9-13). Alexandria, VA: Association For Talent Development.

Bhatt, I. (2015) Curation as a new direction in digital literacy theory. Reviewed proceedings for the Society for Research into Higher Education (SRHE) Annual Research Conference 2015 "Converging Concepts in Global Higher Education Research" (Dec 2015, Celtic Manor, Newport, Wales).

Deschaine, M. E., \& Sharma, S. A. (2015). The five Cs of digital curation: Supporting twenty-first-century teaching and learning. InSight: A Journal of Scholarly Teaching, 10,19-24.

Dunaway, M. (2011). Connectivism: learning theory and pedagogical practice for networked information landscapes. Reference Services Review, 39(4), 675-685. DOI 10.1108/00907321111186686.

Flintoff K, Mellow, P., \& Clark, K. P. (2014). Digital curation: Opportunities for learning, teaching, research and professional development. In Transformative, innovative and engaging. Proceedings of the 23rd Annual Teaching Learning Forum, 30-31 January 2014. Perth: The University of 
Western Australia. Retrieved from

http://ctl.curtin.edu.au/professional development/conferences/tlf/tlf2014/refereed/flintoff.html

Ghaith, G. (2010). An exploratory study of the achievement of the twenty-first century skills in higher education. Education + Training, 52(6/7), 489-498.

Good, R. (2016). The future of education. In A. Anderson \& B. Betts (Eds). Ready, set, curate (pp. 63-65). Alexandria, VA: Association For Talent Development.

Hazari, S., North, A., \& Moreland, D. (2009). Investigating the pedagogical value of wiki technology. Journal of Information Systems Education, 20(2), 187-199.

Jenkins, H., Purushotma, R., Weigel, M., Clinton, K., \& Robison, A. J. (2009). Confronting the challenges of participatory culture: Media education for the 21st century. Cambridge, MA: MIT Press.

Johnson, L., Adams Becker S., Cummins M., Estrada, V., Freeman, A., \& Ludgate, H.(2013). NMC Horizon Report: 2013 Higher Education Edition. Austin, TX: The New Media Consortium.

Johnson, L., Adams Becker, S., Estrada, V., \& Freeman, A. (2015). NMC Horizon Report: 2015 Higher Education Edition. Austin, TX: The New Media Consortium.

Mackey, T.P., \& Jacobson, T.E. (2011). Reframing information literacy as a metaliteracy. College \& Research Libraries 72(1), 62-78.

Mihailidis, P., \& Cohen, J.N. (2013). Exploring curation as a core competency in digital and media literacy education. Journal of Interactive Media in Education. 2013(1):2, DOI:

http://dx.doi.org/10.5334/2013-02

Mills, M.S. (2013). Facilitating multimodal literacy instruction through digital curation. In J. Whittingham, S. Huffman, W. Rickman, \& C Wiedmaier Hershey (Eds.), Technological tools for the literacy classroom, pp. 46-63, Hershery, PA: Idea Group Inc (IGI).

Ng'ambi, D., \& Bozalek, V. (2013). Editorial: Emerging technologies and changing learning/teaching practices. British Journal of Educational Technology, 44(4), 531-535.

Peterson, F. (2016). Media education for the global workplace: Developing employability skills through digital learning. Media Education Research Journal, 6(2), 55-73.

Rheingold, H. (2012). Stewards of digital literacies. Knowledge Quest, 41(1), 53-55.

Salas-Pilco, S.Z. (2013). Evolution of the framework for 21st century competencies. Knowledge Management \& E-Learning, 5(1), 10-24.

Sharma, S. A., \& Deschaine, M. E. (2016). Digital curation: A framework to enhance adolescent and adult literacy initiatives. Journal of Adolescent \& Adult Literacy (in press). 
Weller, M. (2011). A pedagogy of abundance. In The Digital Scholar: How Technology Is Transforming Scholarly Practice (pp. 85-95). London: Bloomsbury Academic. Retrieved from https://www.bloomsburycollections.com/book/the-digital-scholar-how-technology-istransforming-scholarly-practice/ch8-a-pedagogy-of-abundance

Wiley, D., \& Hilton, J., III. (2009). Openness, dynamic specialization, and the disaggregated future of higher education. The International Review of Research in Open and Distributed Learning, 10(5).

Wolff, A., \& Mulholland, P. (2013). Curation, curation, curation. In Proceedings of the 3rd Narrative and Hypertext Workshop (p. 1). ACM.

Wolski, M., \& Richardson, J. (2014). A model for institutional infrastructure to support digital scholarship. Publications, 2(4), 83-99.

\section{Athabasca University}

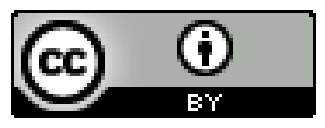

